\title{
Alcohol consumption is a leading risk for morbidity and mortality; public
}

\section{health initiatives needed}

R Lakhan ${ }^{1}$

${ }^{1}$ Doctoral Candidate in Epidemiology, Jackson State University, USA

Chief Editor

Dr. Brijesh Sathian

Technical Editor

Dr. Brijesh Sathian

Formatting Editor

Dr. Brijesh Sathian

\section{Letter to the Editor}

\author{
Corresponding Author: \\ Ram Lakhan, BMR, MS \\ Doctoral Candidate in Epidemiology \\ School of Health Science, College of Public Service \\ Jackson State University, 350 \\ West Woodrow Wilson Drive \\ Jackson, MS 39213 \\ Email: ramlakhan15@gmail.com
}

\section{Dear Editor,}

I read the article authored by Dasgupta et al "Alcohol Consumption by workers in automobile repair shops of a slum of Kolkata: An assessment with AUDIT instrument" with great interest. This article was published in the Nepal Journal of Epidemiology in volume 3, issue 3, 2013 ${ }^{1}$. Alcoholism leads several health, economic and social problems in the lives of people who consume it. It also affects their families and community. Social issues such as violence, suicide, child neglect, work place absent, conflict in relationship, and divorce are some common outcomes of alcohol consumption ${ }^{2}$. Alcohol consumption is very common in all of the countries, races, gender and among different socio-economic groups. Its higher prevalence in developed nations poses a greater safety risk in population ${ }^{3}$. The issue of alcoholism is a public health concern.

Alcohol consumption has been found associated with several health problems. Health effects are very complex and multidimensional. Approximately, 60 medical problems are associated with alcohol consumption ${ }^{4}$. However, eight conditions (neuropsychiatric disorders, gastrointestinal diseases, cancer, intentional injuries, unintentional injuries, cardiovascular diseases, fetal alcohol syndrome, pre-term birth complications and diabetes mellitus) are primarily associated to the alcohol consumption ${ }^{2}$. According to the World Health Organization (WHO), global status report on alcohol and health; alcohol is a leading risk factor for death in the male population between ages 15 to 59 years. Responsible cause of deaths include injuries, violence, and cardiovascular disease/s, which is attributed to the alcohol consumption ${ }^{2}$. It is a great contributor of intentional and unintentional injuries. It is known that all types of injuries including alcohol influenced causes are over 5.8 million deaths every year across the world ${ }^{5}$. The death rate attributed to alcohol consumption is globally higher in male $(7.4 \%)$ than the female (1.1\%) population ${ }^{2}$.

It accounted for high death rates, almost equal to the tobacco and hypertension in $2005^{4}$. The WHO attributes $4 \%$ of deaths to alcohol consumption. This mortality rate is greater than HIV/AIDS, violence and tuberculosis ${ }^{2}$. Health consequences in terms of alcohol related morbidity of South 
East Asian countries are high ${ }^{2}$ (figure 1). Considering the magnitude of the problem, greater public health initiatives are needed. Although, low, lower and middle income (LAMI) countries have lower prevalence of alcohol consumption than high income nations. Looking at the worldwide trend, it may be possible that the alcohol consumption rate increases with the growing economy in LAMI nations in South East Asia that may add a further risk of negative health outcome.

Figure 1: Morbidity of alcohol related disorders in South East Asian countries in population (age 15 + years)

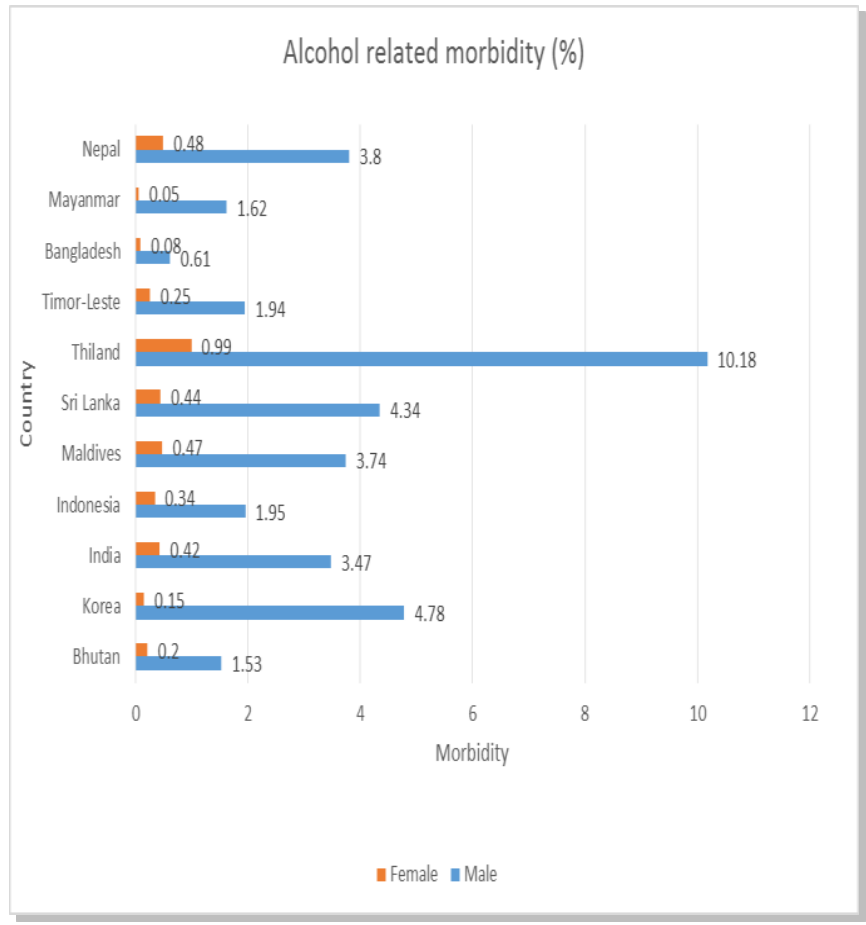

Source: WHO, Global status report on alcohol and health

\section{References}

1. Dasgupta A, Ray S, Pal J, Biswas R, Ray D, Ghosal A. Alcohol Consumption by workers in automobile repair shops of a slum of Kolkata: An assessment with AUDIT instrument. Nepal Journal of Epidemiology 2013; 3(3): 269274.

2. World Health Organization. Global status report on alcohol and health [online] 2011 [cited November 08]. Available from: URL: http://www.who.int/substance_abuse/ publications/global_alcohol_report/msbgsruprofiles.pdf

3. Niemelä O. Biomarkers in alcoholism. Clinica Chimica Acta 2007; 377(1), 39-49.

4. Room R, Babor T, Rehm, J. Alcohol and public health. The lancet 2005; 365(9458), 519-530.

5. Lakhan R. Injury Prevention: A Public Health Concern for India. Nepal Journal of Epidemiology 2013; 3(3), 275-276.

\section{Article Information}

\section{Article history}

Received

$12^{\mathrm{h}}$ November 2013

Received in revised form

$17^{\text {th }}$ November 2013

Accepted

$22^{\text {nd }}$ December 2013 